\title{
O LUGAR SOCIAL E A HISTORIOGRAFIA: A FARROUPILHA E A CONSTRUÇÃO DE SEU SENTIDO
}

\author{
THE SOCIAL PLACE AND HISTORIOGRAPHY: FARROUPILHA \\ AND THE CONSTRUCTION OF ITS MEANING
}

\begin{abstract}
Fabrício Antônio Antunes Soares ${ }^{1}$ Airton Adelar Muller ${ }^{2}$

RESUMO: O presente artigo quer examinar como o lugar social, da operação historiográfica, se articula com a construção de sentido narrativa da historiografia. Duas fontes bibliográficas foram selecionadas para tal investigação. Ambas são de períodos históricos específicos. Uma fonte é $A$ história da República Rio-Grandense, lançada em 1882, de J. F. de Assis Brasil, a outra é $O$ sentido e o espírito da Revolução Farroupilha, de J. P. Coelho de Souza, publicada em 1936. Portanto, o problema que norteia esta reflexão é saber como cada lugar social distinto contribuiu, em épocas diferentes, a sua maneira para a construção de sentido da Farroupilha. Por fim, o artigo infere que a operacionalidade do lugar social de produção da historiografia foi decisiva como elemento da constituição de sentido das narrativas sobre a Farroupilha nas duas fontes analisadas.
\end{abstract}

PALAVRAS-CHAVE: História intelectual; História da historiografia; História dos conceitos; Teoria da história; Farroupilha.

ABSTRACT: The present work wants to examine how the social place, of the historiographic operation, is articulated with the construction of the narrative sense of historiography. Two bibliographic sources were selected for this investigation. Both are from specific historical periods. One source is $A$ História da República Rio-Grandense published in 1882 by J.F. de Assis Brasil, the other is $O$ Sentido e o Espírito da Revolução Farroupilha, by J.P. Coelho de Souza, published in 1936. Therefore, the problem that guides this reflection is to know how each distinct social place contributed, at different

\footnotetext{
* Este artigo é o resultado de pesquisas do projeto de pesquisa "Os sentidos da Farroupilha: entre a poética, a epistemologia e o agir", ligado ao PPGH-UPF, linha "Cultura e Patrimônio", e ao grupo de pesquisa NEMEC-UPF (Núcleo de Estudos de Memória e Cultura).

${ }^{1}$ Professor do curso de história e do PPGH da UPF, doutor, endereço: Campus I/UPF - BR 285, IFHC/PPGH, Bairro São José - CEP 99052-900,e-mail: fabricioantunessoares@ gmail.com, tel.: (54) 3316-8339

${ }^{2}$ Professor do PPGDR da Unijuí, doutor, endereço: Rua do Comércio, 3000, Bairro

Universitário. CEP: 98700-000, e-mail: airton.mueller@unijui.edu.br, tel.: (55) 3332 0200,
} 
times, its way to the construction of Farroupilha's meaning. Finally, the article infers that the operationality of the social place of production of historiography was decisive as an element of the constitution of meaning in the narratives about Farroupilha in the two analyzed sources.

KEYWORDS: Intellectual history; History of historiography; history of concepts; Theory of history; Farroupilha

Introdução: A escrita da história e sua operacionalização

$\mathrm{O}$ que fabrica o historiador quando 'faz história'? Para quem trabalha? Que produz? (CERTEAU, 2007: 65)

Esse artigo analisa a operacionalidade que o lugar social (CERTEAU, 2007: 66-77) tem com a historiografia. Com ele, procuramos avaliar como o lugar social se articulou e determinou a escrita da história sobre a Farroupilha. Para alcançar esse objetivo, tomamos como demonstração e comprovação, do lugar social na escrita da história da Farroupilha, o conceito de federalismo, isto é, como é possível perceber o lugar social, na historiografia sobre a Farroupilha, a partir do conceito de federalismo. Dito isso, partimos do pressuposto que não há como eliminar a idiossincrasia do lugar de onde o(a) historiador(a) escreve e do campo científico no qual desempenha uma pesquisa. O lugar de produção é um indício permanente da produção do(a) historiador(a). Examinar a história como uma operação - ou seja, a operação historiográfica - significa analisá-la como a articulação entre a) um lugar social, b) práticas científicas e c) a escrita de um texto (CERTEAU, 2007: 66). Porém, dos três elementos da operação historiográfica elencados por Michel de Certeau, aqui aprofundaremos o lugar social.

Para compreender-se, portanto, a história da historiografia sobre a Farroupilha, partimos do pressuposto de que qualquer investigação histórica se encadeia com um lugar e suas determinações tanto sociais e culturais como políticas e econômicas. Isso acarreta uma forma de proceder na historiografia limitada por condições inerentes ao lugar de sua produção. Assim, é em relação a um determinado lugar social que se organizam os métodos, que se constituem os documentos e se apresentam os problemas da pesquisa. Além disso, o lugar é uma instituição do saber (CERTEAU, 2007: 69) que tem, por um lado, uma 
extensão externa, associada a outras instituições e conjuntos corporativos, e, por outro, uma extensão interna, o estabelecimento de um saber inseparável de uma instituição social. Esse é, então, um dos requisitos do desenvolvimento científico da operação historiográfica. Portanto, além de fornecer a solidez social à escrita da história, a instituição também torna-a possível.

Além do mais, seria a mesma dinâmica social que estabelece a instituição e os conceitos que a circundam. Ambos, com funções díspares porém imbricados, e os quais nenhum é (necessariamente) a razão elementar do outro. De tal forma, a sociedade e a composição de sentido se ajustam sem se hierarquizar. Portanto, seria abstrata a historiografia que reprime ou omite sua articulação com um lugar social. De tal modo que esta articulação faz parte do procedimento científico, mesmo que a circunstância social seja o não dito na narrativa do historiador. Logo, não é possível considerar o texto historiográfico como autônomo à instituição em conformidade à qual ele se constituiu. $\mathrm{O}$ texto, consequentemente, avoca seu vínculo com a instituição. Como exemplo, Certeau (2007) analisa o 'nós', pois o 'nós' do(a) historiador(a) alude a um pacto, um acordo acadêmico, porque no texto o 'nós' é a representação daquele acordo que organiza o eu do(a) historiador(a) no 'nós' de uma pesquisa acadêmica coletiva. E assim, Certeau (2007) compara a relação da historiografia e do lugar social com a do automóvel feito em uma fábrica. $\mathrm{O}$ trabalho historiográfico é, desse modo, entendido como uma fabricação especializada e coletiva.

Disso surge que a historiografia é a obra de um lugar e, entre suas hierarquias e seus códigos, entre a seleção da documentação até a escrita do passado, o fazer do(a) historiador(a) é referente à estrutura da sociedade. Dessa forma, uma transformação da sociedade aquiesce ao(à) historiador(a) um distanciamento quanto àquilo que se converte em uma história narrada, pois muitos(as) historiadores(as) aceitam como premissa de seu entendimento a arquitetura teórica de seu lugar institucional. E, ao longo do processo historiográfico, o(a) historiador(a) não versaria sobre aquilo que o delimita, porque, em muitos casos, para Certeau (2007), há posições a acatar e 
influências a requerer e, assim, o não dito está sub-reptício no texto. Portanto, enquanto é preciso entender como a historiografia reapresenta o passado, é preciso também compreender como a historiografia opera no interior da sociedade. Assim, a função do lugar é, de antemão, proibir e permitir tipos de uso, construções e representações do passado. É desse modo que a historiografia se definiria "por uma relação da linguagem com o corpo (social) e, portanto, também pela sua relação com os limites que o corpo impõe." (CERTEAU, 2007: 76).

Neste texto, devido à operacionalidade do artigo, optamos por fazer um corte temporal por obras mais significativas politicamente em seu período. Foram escolhidos dois períodos de escrita da história sobre a Farroupilha: a) a geração de 1870 , b) o centenário da Farroupilha $(1935)^{3}$, para averiguar e testar a operacionalidade do lugar social, tal como definido por Certeau (2007), na escrita da história.

\section{A Farroupilha (I): entre a geração de 1870, o Clube Vinte de Setembro e o federalismo}

No Rio de Janeiro foi publicado, em 3 de dezembro de 1870 no jornal $A$ República, o manifesto do movimento republicano no Brasil, que tinha em destaque as ideias de democracia e federalismo, além de críticas ao poder pessoal do imperador e à sua interferência nos resultados eleitorais. Em sua maioria, o manifesto fora assinado por dissidentes do Partido Liberal. A grande maioria era da província de São Paulo, cujas demandas desta e de outras mais periféricas eram tidas como mal retratadas na rígida estrutura de representação da política imperial. A defesa do federalismo levou muitos deles para o campo reformista. Desse modo, segundo Alonso (2002), no fim do Brasil Império formou-se uma nova geração de intelectuais que questionavam as instituições e os valores monárquicos. Essa nova geração de letrados, durante o fim do período monárquico, estava em busca de dados para compreender a conjuntura que vivenciavam e conectar-se com uma atuação política. Disso, a inclusão de

\footnotetext{
${ }^{3}$ Sobre a escolha dessa divisão, ver: Soares (2016).
} 
novos aspectos intelectuais é entendida como a busca de novos recursos teóricos para suscitar uma explicação da crise social e proporcionar vias alternativas ao poder monárquico. Desse modo, "este é o sentido do 'positivismo', do 'cientificismo', do 'novo liberalismo': são modalidades de crítica ao status imperial" (ALONSO, 2000: 45). Portanto, as obras da geração de 1870 são respostas ao contexto de crise política. Houve uma reelaboração intelectual e política que provocava a manipulação do cânon de personagens, efemérides e símbolos nacionais do status quo imperial, além de uma busca por meio da história de edificar "uma tradição alternativa à elite imperial" (ALONSO, 2000: 48) a partir de seu novo panteão. Assim, movimentos republicanos do passado que haviam sido esquecidos são recuperados.

Os estudantes sul-rio-grandenses da Faculdade de Direito de São Paulo, que fizeram seus cursos preparatórios nas escolas particulares da Capital riograndense na década de 1870, presenciando o auge da atividade do Partenon Literário e que conheceram a propaganda de Apolinário Porto Alegre em favor da república, decidiram entrar em uma empreitada para escrever uma história concisa da Província (LAZZARI, 2004). Almejava-se concretizar uma obra de publicidade, a ser lançada a 20 de setembro de 1882, data do aniversário da Farroupilha. Em relação à produção histórica anterior, os republicanos pretendiam escrever uma história científica, diferente do projeto do IHGB (CEZAR, 2003). Era objetivo dos republicanos explicar o significado dos episódios históricos confrontando as decisões políticas com o caráter riograndense tramado pelas influências naturais da raça e do ambiente. A tática era instigar o sentido de uma identidade original entre os rio-grandenses para persuadi-los da ascendência do regime federativo sobre a centralização. Os novos republicanos rio-grandenses da década de 1880 acreditavam poder estabelecer sua racionalidade e cientificidade e se colocaram em ação para serem hegemônicos no comando do Partido Republicano ${ }^{4}$.

\footnotetext{
${ }^{4}$ Sobre a formação intelectual de Assis Brasil na Academia de São Paulo, ver: Antoniolli (2017: 28-52).
} 
Integravam o Partido Republicano Rio-grandense jovens há poucos egressos da Academia de São Paulo, então um amplo núcleo difusor do ideal republicano. Ali se fundara o Clube Vinte de Setembro, filiando seu pensamento político ao dos farroupilhas, tal qual fizeram os(as) liberais e republicanos(as) da geração anterior (PICCOLI, 1993: 156). Entre os(as) integrantes do PRR que se dedicaram à escrita historiográfica da Farroupilha estava o jovem estudante de direito Joaquim Francisco de Assis Brasil (18571938) $)^{5}$. A pregação republicana marchava para saídas radicais e alguns acadêmicos rio-grandenses, estudantes na Academia de São Paulo, agremiados no Clube Vinte de Setembro, iriam desfechar críticas à ordem imperial. Desse modo, houve um projeto político-historiográfico desse clube sobre como escrever a Farroupilha. Isto é, intentaram o reconhecimento de outro passado que se acomodasse a seu projeto político: o federalismo republicano ${ }^{6}$.

Assis Brasil considerou seu livro a História da República RioGrandense, publicado em 1882, uma consequência de ideias anteriormente expostas por ele, no livro República Federal, pois estava convencido de que as revoluções de maior relevo no país contiveram o imperativo "do estabelecimento do sistema racional da federação que também se pode chamar - sistema de liberdade." (ASSIS BRASIL, 1982: VII). Nesse caso, a revolução rio-grandense seria a mais aproximada desse ideal: a federação. Desse modo, o posicionamento político/historiográfico de Assis Brasil confrontava-se abertamente com o de Tristão Alencar Araripe (1881), que três anos antes se pronunciara no IHGB contra a Farroupilha e o seu sistema político (HRUBY, 2012: 152-228).

Portanto, para Assis Brasil o relacionamento entre a Província sulina e a Império brasileiro precisava ser examinado, começando pelas causas do meio cósmico e, depois, averiguando os motivos do episódio revolucionário. Nessa investigação, o que primeiramente sobressai é o contraste entre o Brasil e o Rio

\footnotetext{
${ }^{5}$ Sobre a biografia e formação política de Assis Brasil, ver: Love (1975, p. 31-32) e Antoniolli (2017: 20-27).

${ }^{6}$ Sobre a propaganda republicana e o uso da Farroupilha em Assis Brasil, ver: Saccol (2013) e Tovo (2019).
} 
Grande. Na avalição do autor, não existiria Província mais distinta em relação à nação que o Rio Grande e, assim, o que a 'ordem natural' do meio determinava era que as instituições que a cobrissem não fossem contrárias à sua própria natureza (ANTONIOLLI, 2017: 78-93). Um sistema racional de instituições políticas não poderia ser mais do que o espelho da estrutura sobre as quais se funda. Para Assis Brasil (1982), o sistema político e o código jurídico imperial tinham a finalidade extravagante de equiparar aquilo em que a natureza tinha instituído uma congruente heterogeneidade. Desse modo,

Os sucessos do Rio Grande [a Farroupilha] foram uma triste comprovação desta verdade. Grande exemplo, cuja lição eloquente parece, entretanto, não ter até hoje servido àqueles a quem se destinava. Uma organização baseada nos elementos naturais, uma organização federativa, para dizer tudo, estabelecida no tempo oportuno, na qual os grandes órgãos deste extraordinário país exercessem livremente as suas funções próprias, cooperando livremente também para a vida do todo - teria aparado os reduplicados golpes que por vezes estiveram prestes a cortar para sempre o fio da integridade nacional. A liberdade é em tudo uma condição de vida e, por conseguinte, de ordem; quiseram substituí-la pela centralização atrofiante; o resultado foi o que se viu: um protesto enérgico da natureza. (ASSIS BRASIL, 1982: 3637)

Segue Assis Brasil que, desde a época colonial, o Rio Grande fora diferente do resto do Brasil, o que lhe moldou um caráter próprio. A população tornou-se guerreira e protegeu os seus interesses com recursos próprios, habituando-se ao propósito da Independência. Com a Independência do Brasil, o novo regime não era mais do que uma extensão do velho. A província permaneceu sendo governada como uma capitania, com apenas uma alteração: o governo central da jovem metrópole operava mais diretamente do que o da antiga metrópole, de modo que os males da centralização se agravaram ainda mais. Para Assis Brasil, o governo do Rio de Janeiro tinha o defeito de não conhecer o povo e a terra que iriam administrar, além disso, seguiu-se a perda da Cisplatina em 1828. Desse modo, a confiança no governo geral estava destruída. O Rio Grande ficou pobre e aniquilado. O governo central causava guerras, devastava a província, explorava as suas fortunas de todas as maneiras 
e usava os serviços dos seus aguerridos filhos. Também, os impostos eram elevados, onerando aquelas indústrias cujo desenvolvimento mais se deveria incentivar. Segundo o autor, o charque e o trigo iam restringindo-se em lugar de progredir. Essas eram as principais riquezas da província que o governo central deprimia sob o peso dos impostos. A consequência nefasta foi fatal:

Nunca foram tão evidentes os males da centralização, isto é, da ausência de liberdade. $O$ governo central não conhecia as necessidades da província, e, se as conhecia, não as sentia e, portanto, não tratava de dar-lhes remédio; por outro lado a iniciativa local não existia, não podia existir num sistema em que toda a vida confluía para o centro. (ASSIS BRASIL, 1982: 45-46)

Segundo o autor, os que se esclareciam sobre a situação política não poderiam deixar de ser oponentes naturais do governo central que tantas vezes extraía tudo da província, sem lhe oferecer coisa nenhuma em troca. Os aborrecimentos, a animosidade, as antipatias despertavam. A doença de que padecia a província era a ausência de liberdade, que significa a faculdade de existir altivamente por si, desse modo "Estava rasgada a senda da federação." (ASSIS BRASIL, 1982: 47). A população não demorou em lançar-se contra o governo imperial, e este acontecimento foi comum em todo o Império. Para Assis Brasil (1982), seria com a Farroupilha que se atestou o apelo inexaurível do país pelo princípio da federação e que mais tarde o teria protegido do torpor que disseminou a pressão centralizadora. Isso porque "No Rio Grande, a federação era a ideia culminante dentre todas as aspirações liberais.” (ASSIS BRASIL, 1982: 54). Para ele, nenhuma evidência permitiria acreditar que existisse por aquele período, deliberada firmeza republicana e, além disso, a democracia era rechaçada por todos os patriotas liberais. O historiador da geração de 1870 acreditava que os farroupilhas nunca pretenderam a separação da província. O que queriam era "estabelecer a federação em todo país, o que também era ideia comum a todos os brasileiros mais ilustres daqueles tempos." (ASSIS BRASIL, 1982: 73). Embora as ocorrências forçassem os farroupilhas a proclamarem-se independentes, em todos os atos oficiais do temporário 
governo em que havia menção à separação da província surgia específica a ideia da federação.

Desse modo, fica clara a articulação entre a escrita da história de Assis Brasil e o seu lugar de operação historiográfica. Tanto como participante intelectual da geração de 1870 como participante do Clube Vinte de Setembro, da Faculdade de Direito de São Paulo. Assim, sua crítica política à monarquia ganhou um meio através do Clube Vinte de Setembro e sua crítica historiográfica através da geração de 1870. Portanto, articulando-se o lugar de operação historiográfica com a narração historiográfica, surge, nas linhas do livro de Assis Brasil, um federalismo como futuro para o seu Brasil contemporâneo, mas já realizado, no passado, pela Farroupilha.

\section{A Farroupilha (II): entre o IHGRGS, a Revolução de 30 e o federalismo}

Foi no ano de 1920 que se fundou o Instituto Histórico e Geográfico do Rio Grande do Sul (IHGRGS), isto é, a decisiva institucionalização da historiografia em um momento de constituição de uma narrativa histórica que integrava o Rio Grande do Sul com o Brasil (MARTINS, 2015: 26-33). Assim, "O estado sulino assume um compromisso com a História e financia as pesquisas, delegando responsabilidades a seus funcionários para a execução de trabalhos." (GUTFREIND, 1992: 20). Nisso, ressalta-se um empenho em inventar uma representação do Rio Grande do Sul que se aproxime do Brasil, porque

A Revolução de 30 leva ao poder um presidente gaúcho, e é nesse contexto, principalmente nos anos 20, na luta para alcançar o poder em nível nacional e legitimar essa posse, que se coloca o interesse em demonstrar historicamente a identidade brasileira do estado sulino. (GUTFREIND, 1992: 20)

A historiografia foi empregada como uma ferramenta e seus operadores foram os historiadores que, em muitos casos, eram os políticos rio-grandenses (MARTINS, 2015: 34-52). A brasilidade do Rio Grande do Sul torna-se, desde sempre, um padrão no entendimento do passado sulino. O padrão teórico- 
metodológico que adotam tem, a partir de então, nas condições físicas, a base do processo histórico sulino. Haveria um modelo determinista para o qual a conformação geográfica de cada país contém uma fatalidade inevitável e

Criar a imagem de um Rio Grande do Sul brasileiro, forte, pujante, com líderes capazes de estarem à frente do poder nacional, justificando seu esforço para alcançá-lo, e finalmente conseguindo, com a Revolução de 1930, foi a tarefa que os construtores da História Gaúcha se impuseram desde a década de 1920. (GUTFREIND, 1992: 22)

A comemoração do centenário da Farroupilha atenderia à necessidade de afirmação de uma nova lógica entre as memórias regional e nacional que se estabeleciam como republicanas desde o fim do século XIX. A partir de 1930, a rearticulação da Farroupilha com a memória nacional exigia "mais do que no contexto das reivindicações federalistas do século XIX, a sua inserção na tradição republicana nacional.” (RODRIGUES, 2013: 178). Portanto,

O movimento, que manteve durante dez anos uma guerra contra o Império, tornava-se não somente digno e glorioso, mas também patriótico e indispensável à integridade da nação! Após uma verdadeira operação de glorificação, nos anos precedentes, em relação às individualidades farroupilhas [...] o próprio caráter do evento sofria uma releitura. A continuidade entre os ideais republicanos de 1835 e os de 1889 e o caráter brasileiro do movimento são explicitamente estabelecidos. (RODRIGUES, 2013: 179)

De acordo com Gutfreind (1992), a consequência foi a conexão da Farroupilha à memória histórica nacional como um movimento revolucionário, republicano, federalista, brasileiro e patriótico. A memória da Farroupilha era disputada em distintas versões, não apenas na esfera do IHGRGS, mas também nos jornais e nas comissões oficiais organizados para as comemorações do centenário $^{7}$, sobressaindo-se a tese do abrasileiramento da Farroupilha. Desse modo,

Em 1935, o centenário da Farroupilha foi comemorado com grandes eventos: exposições industriais, publicações, edificações de parques urbanos, temporadas líricas, estreias de peças teatrais e reapresentações de uma ópera sobre o drama dos farrapos. Um esforço do Governador, General

\footnotetext{
${ }^{7}$ Sobre a comemoração do centenário da Farroupilha, usando como fontes os jornais de Porto Alegre, ver: Silva (2012).
} 
José Antônio Flores da Cunha, para fazer conciliar a tradição campeira e regionalista com a modernidade urbana e industrial. (AXT, 2009: 37)

O processo de conversão da Farroupilha, nas vésperas de seu centenário, simultaneamente em objeto cívico nacional e objeto historiográfico provocava reações apaixonadas por parte dos intelectuais. Entretanto, uma vez respeitados os procedimentos científicos legitimados pelas instituições, os textos dos historiadores logo se prestavam ao uso político, como se pode verificar na continuidade das conferências comemorativas do centenário farroupilha (MARTINS, 2015: 106-107).

Um dos intelectuais do período que se envolveu nesse projeto político/historiográfico foi José Conceição Pereira Coelho de Souza, nascido em Porto Alegre, em 1898. Souza bacharelou-se em direito em 1924, foi deputado estadual de 1935 a 1937, secretário da Educação e da Cultura do Rio Grande do Sul de 1937 a 1945. Também foi professor de História e Filosofia da Educação, na Universidade Federal do Rio Grande do Sul (UFRGS). Pertenceu ao IHGRGS e à Academia Rio-Grandense de Letras (ARL) (MARTINS, 1978). O sentido e o espírito da Revolução Farroupilha, de J. P. Coelho de Souza, mesmo sendo publicado só em $1936^{8}$, resulta de seu discurso pronunciado na sessão solene da Assembleia Legislativa, em 20 de setembro de 1935, comemorando a Farroupilha. Em geral, três pontos perpassam a obra: a) a brasilidade da Farroupilha; b) o não separatismo da revolução; c) o seu federalismo.

Souza (1945) começa sua narrativa historiográfica afirmando que há uma centúria as lanchas, de uma pobre província desamparada, estremeciam ao estrondo de uma marcha heroica, desafiando de maneira altaneira o julgamento futuro da História. Segue o autor que a Farroupilha seria os feitos de uma epopeia, os momentos de consagração, a beleza épica, um poema, uma canção de sublimação na glorificação dos antepassados gaúchos e, dessa forma, seria

\footnotetext{
${ }^{8}$ O livro de Coelho e Souza intitulado No centenário farroupilha: discursos pronunciados nas comemorações, publicado em 1936, em que consta o capítulo "O sentido e o espírito da Revolução Farroupilha”, foi um dos requisitos para seu ingresso no IHGRGS.
} 
necessário corroborar as "atitudes do passado, devemos mostrar aqueles heróis - para sua maior glória; para nossa própria justificativa; para que o Brasil, de uma vez por todas, faça justiça à nossa conduta, no pretérito e no tempo presente." (SOUZA, 1945: 17). Nessa citação já é possível perceber o uso do passado Farroupilha para as intenções políticas presentes em 1935.

$\mathrm{O}$ escritor segue dizendo que historiadores pouco sólidos expuseram a Farroupilha como um ato antibrasileiro, separatista. Um dos principais focos dessa crítica é Alfredo Varella (1933), que dois anos antes havia lançado seu principal livro sobre a Farroupilha, em que afirma sua umbilical conexão com as Revoluções Cisplatinas e seu intrínseco separatismo (SILVA, 2010). Contudo, ao contrário disso, um enorme fluxo de historiadores exibe a Farroupilha nas suas exatas particularidades, como um acontecimento brasileiro, pois as suas causas gerais, predisponentes, são estritamente brasileiras:

A primeira dessas [causas predisponentes] foi o federalismo, que é uma tendência orgânica do povo brasileiro. No inconsistente da nossa evolução histórica [...] só a ideia descentralizadora se afirma de norte a sul, através de todos os estádios políticos do Brasil, com estranha pujança [...] É o lastro de todos os programas liberais e partidos progressistas; é a causa desencadeante de todas as lutas civis que ensanguentaram o país. (SOUZA, 1945: 19)

Portanto, de acordo com Souza (1945), o federalismo foi uma condição do espírito pátrio, ambição dominadora que a tudo arrostou. $\mathrm{O}$ federalismo encerraria a sua raiz em um elemento, que antes de ser brasileiro é americano, do norte ao sul. Acredita o autor que a característica de uma disposição ao agrupamento da massa de população brasileira causa todo um conjunto intrincado de implicações históricas. Por isso, esse fato heterogêneo firmou-se no Brasil colonial, segundo o autor, na massa amorfa e ganglionar da população. Tais nódulos da povoação procedem da condensação de três raças distintas: branco, negro e indígena. Depois viria o mestiço. Segundo Souza (1945), ao conviver e copular entre si, as três raças, era lógico que em pouco tempo os aglomerados da população apresentassem os mais diversos tipos morfológicos, as mais contrapostas mentalidades e os caráteres mais adversos. 
Em seguida, a dispersão desses nódulos populacionais se realizou em uma incomensurável diversidade geográfica. Essa extraordinária largueza de sustentação geográfica concluiu a construção da miscigenação acidentada, entre composições morfológicas híbridas e o meio físico amplo e diverso. Contudo, para o autor, por cima dessas diversidades de disposição étnica e geográfica, imperava a completa igualdade no estado mental e moral desde a colônia. A propósito dessa unidade espiritual é que se constituía a coesão do Brasil. De tal modo que

Se tivermos em vista, agora, que as dessemelhanças sociais se refletem sobre toda a vida do agregado, desde os métodos de trabalho até à organização dos poderes públicos - teremos alcançado, plenamente, por que o federalismo é uma tendência orgânica do povo brasileiro. Os primeiros federalistas agiram por natural instinto. (SOUZA, 1945: 22)

Souza (1945) afirma ainda que os conflitos federalistas são os mais naturais entre os que sacudiram a nação, tanto que o autor remonta o federalismo aos períodos mais longínquos da história nacional. Para ele, desde o Brasil colônia "o federalismo lá estava, em semente, aguardando um momento que lhe propiciasse o germinar." (SOUZA, 1945: 22). Assim, à medida que os farroupilhas organizavam-se, a descentralização advinha na autonomia local, portanto, da colônia ao primeiro Império, o federalismo era orgânico ao povo brasileiro e "desse esforço decorre, claro e irretorquível, que a história política do Brasil, de norte a sul, é, antes de tudo, um grande esforço em prol da Federação." (SOUZA, 1945: 28).

Para ele também, junto com o federalismo, outra causa predisponente da Farroupilha foi a abdicação de Dom Pedro I, em 7 de julho. No período, foi considerada uma causa predisponente, porque o processo da abdicação não fora levado às últimas consequências, o que seria uma república federativa. Portanto, as causas gerais da Farroupilha eram, na ótica de Souza (1945), todas naturalmente brasileiras.

$\mathrm{Na}$ argumentação desse autor, também haveria as causas locais da Farroupilha, essas chamadas de desencadeantes: o ressentimento resultante do descaso do Centro pelo Rio Grande e a política reacionária da Corte. Segundo 
Souza (1945), o Rio Grande do Sul em tudo cedia e não exigia nada de volta em relação ao Centro. Contudo, não foram querelas em oposição à Pátria brasileira, mas sim em desacordo aos governos centrais. E tais causas, as predisponentes e as desencadeantes, interpenetram-se e configuram a Farroupilha. Também, considera o autor, poder-se-ia caracterizar que o período da Farroupilha foi a diligência, ignorada e rejeitada de adaptação do liberalismo sul-rio-grandense com a política do centro. Para Souza (1945), o rio-grandense sempre fora liberal e, da colônia à abdicação de D. Pedro I, o liberalismo rio-grandense assumiu fisionomias e horizontes, de tal modo que no período da abdicação o liberalismo sulino estava impecavelmente acentuado. Também é preciso reconhecer a existência, à época, de um estável grupo político conservador. Porém, a maior parte do povo era liberal. Mas os liberais tinham uma divisão interna: os moderados e os exaltados e, assim, "Moderados e exaltados encontravam-se [...] sobre um denominador comum: o ideal federalista, que a Abdicação exaltara no Rio Grande. Era essa a ideia mestra que os impulsionava." (SOUZA, 1945: 38).

Para Souza (1945), o espírito da Farroupilha, na sua etapa prévia, era igual ao das outras revoltas regenciais. Ela nunca foi, em espírito, antibrasileira e, em seu sentido, separatista. Por conseguinte, no vinte de setembro, a primeira fase da Farroupilha, foi quando os liberais rechaçaram os conservadoresrestauradores na extremadura sul da nação. Para o autor, a segunda fase da Farroupilha foi a da separação e a da República. Fora a administração inábil e ultrajante do governo central que lançou a Farroupilha no rumo dos exaltados. O expediente separatista, em 1836, foi produzido pela imposição dos fatos. Segundo ainda Souza (1945), o farroupilhas foram ignorados pelo poder central e acossados como insurgentes sem ideal, restando, assim, somente a sujeição ou a luta. De modo que

a seção seria transitória: o Continente daria o grande exemplo, estimularia a vitória dos princípios republicanosfederativos nas demais províncias e, por fim, voltaria, sob a Federação, ao convívio dos brasileiros [...] A separação era meio e não fim. Secionado do Brasil - o Rio Grande não foi menos brasileiro que antes. (SOUZA, 1945: 48) 
Conforme o autor, cem anos após o início da Farroupilha, ou seja, no presente da escrita de Coelho de Souza, a 'nossa' brasilidade (dos sul-riograndenses) fora novamente recusada. Sequer a paz em 1845 ou os 'nossos' martírios de sangue puderam fazer que tal desconfiança desonrosa fosse rejeitada. $\mathrm{O}$ autor pede aos céus que, de uma vez por todas, não existam no Brasil indivíduos de má fé, capazes de reproduzir o agravo. Assim, o riograndense devota-se ao seu torrão natal apenas para servir ao Brasil. A Farroupilha fora "Brasileira nos seus motivos; brasileira nos seus objetivos; gaúcha só no seu ímpeto e no sacrifício - colimava o bem-estar do Continente e o respeito à sua dignidade, aliados à unidade e à grandeza do Brasil.” (SOUZA, 1945: 66).

No fim do livro, o autor concluiu que foi o espírito da época que impôs a imortalidade aos farroupilhas. Souza (1945) afirma que a tenacidade dos farroupilhas 'arrebata-nos' da mesma forma que o seu estoicismo no sacrifício. Assegura ainda que a sua bravura criou uma epopeia no sul do Brasil. Assim, no fim do conflito os 'descamisados' heroicos estabeleciam exigências de paz ao Império. Como consequência, Souza (1945) solicita ao(à) leitor(a) do presente e do futuro que 'Orgulhe-nos... Ufane-nos' da Farroupilha. Por fim, ele entende que começava, em 1935, um novo ciclo. Na sequência, declara que toda obra do presente seria ininterruptamente uma consequência da intensidade e da potência da história, por isso pede que seus contemporâneos(as) e leitores(as), do presente e do futuro, impregnem-se dos exemplos dos farroupilhas e venerem as suas atitudes, pois estas estimulariam a cumprir a tarefa, a missão de 1835 no presente, com amor ao passado e respeito à tradição. Seria perante os farroupilhas que a geração de 1930 deveria assumir os compromissos do presente do passado e do futuro.

Ora, no livro de Coelho de Souza sobre a Farroupilha as marcas do lugar de escrita fazem-se presentes. O IHGRGS e a Revolução de 30 são as balizas norteadoras. A escrita da história, em Souza (1945), articula-se com esses dois contextos. O IHGRGS (norte intelectual) e a Revolução de 30 (o direcionamento político). Dessa articulação surge o federalismo da Farroupilha, 
um federalismo buscado no passado farrapo para comemorar e nortear a política varguista.

\section{Considerações finais}

Esse artigo buscou compreender como se articulou, na historiografia sobre a Farroupilha, o lugar de produção na narrativa histórica. Para isso, foi averiguado o conceito de federalismo na escrita da história. Foram selecionados dois períodos da escrita da história sobre a Farroupilha em que o uso do conceito de federalismo foi central na constituição da explicação dos historiadores à época. Desse modo, um primeiro ponto a observar é o lugar de produção dos respectivos historiadores selecionados. Assis Brasil (1982) escreveu como integrante do Clube Vinte de Setembro, isto é, envolvido em questionar a monarquia e demonstrar que a república-federal seria a melhor institucionalização política para o Brasil contra o centralismo da Corte. Souza (1945) escreveu como aliado político de Getúlio Vargas, ou seja, fez carreira política dentro do aparelho do Estado como figura intelectual do varguismo. Nesse período, a produção do conhecimento histórico dava-se no IHGRGS. Ele acreditava que o federalismo dos farroupilhas estava o cerne da Revolução de 30 .

Como afirmamos inicialmente neste artigo, a operação historiográfica, tal como definida por Certeau (2007), tem três elementos: o lugar social, as práticas científicas e a escrita de um texto. Priorizamos, aqui, a investigação do lugar social. Porém, para concluirmos, acreditamos que o próprio artigo e futuras investigações sobre o tema devem se abrir para os outros dois elementos da operação historiográfica. Assim, já é possível destacar - contudo, precisando ainda aprofundar a pesquisa - as práticas científicas dos autores por ora analisados. É possível averiguar as concepções teóricas da história que informam o uso do conceito de federalismo. Nesse quesito, o menos destacado é Souza (1945), enquanto Assis Brasil (1982), como participante da geração de 1870, introduzia o cientificismo histórico europeu através de autores como Henry Thomas Buckle e Hippolyte Taine e fazia do conceito de federalismo 
uma necessidade histórica do meio geofísico brasileiro. Souza (1945) não chega a expor uma concepção de teoria da história, mas está diluído em seu texto um cientificismo/positivismo difuso quando aborda que há leis gerais e locais na história (BOEIRA, 1980: 45-54). Assim, o federalismo seria umas das leis gerais, assumindo um sentido, na narrativa do historiador, de uma natureza orgânica que comunga todos os brasileiros.

Um último ponto a destacar é a escrita da história em sua dimensão retórica. Assis Brasil (1982) tem uma retórica de confronto com as instituições monárquicas e faz uso do conceito de federalismo para enfrentar seus(suas) adversários(as) políticos(as) na Província e na Corte, potencializando esse conceito como uma necessidade política e histórica do Brasil. Souza (1945) estava com sua escrita da história envolta no período comemorativo do centenário da Farroupilha. Desse modo, em seu texto o conceito de federalismo é usado como forma de glorificar e exaltar a Farroupilha, mas não só ela como também os seus continuadores no presente: os próceres da Revolução de 30. A sua retórica faz igualar em glórias os farroupilhas e seus(suas) companheiros(as) políticos(as) da geração de 1930.

Ao fim, em cada fonte analisada nesse artigo nota-se como articulou-se o lugar social de produção na narrativa histórica, o que forneceu um sentido a Farroupilha a partir do conceito de federalismo próprio ao seu tempo e aos interesses políticos do momento. Em cada emprego do conceito de federalismo estava uma instituição diferente. Em cada texto, o federalismo ajudou a criar uma paisagem alternativa da Farroupilha. O lugar social, o federalismo, a historiografia e a política, em cada narrativa, tiveram um sentido distinto. Portanto, é a articulação de ambos que criou uma representação histórica, isto é, um sentido, específico a cada período.

\section{Referências}

ALONSO, Angela. Crítica e contestação: o movimento reformista da geração 1870. In: Revista brasileira de ciências sociais, v. 15 , n. ${ }^{\circ} 44$, out. p. $35-55$, de 2000 .

ALONSO, Angela. Ideias em movimento: a geração de 1870 na crise do BrasilImpério. São Paulo: Paz e Terra, 2002. 
ANTONIOLLI, Juliano Francesco. "Tão longe quanto a previsão científica possa alcançar": a experiência do tempo da geração republicana da Faculdade de Direito de São Paulo (1878-1882). Tese (Doutorado em História). Universidade Federal do Rio Grande do Sul (UFRGS), Porto Alegre, 2017.

ARARIPE, Tristão de Alencar. Guerra civil no Rio Grande do Sul: memória acompanhada de documentos lida no Instituto Histórico e Geográfico Brasileiro. Porto Alegre: Corag, 1986. (1881)

ASSIS BRASIL, Joaquim Francisco. História da República Rio-Grandense. Porto Alegre: ERUS, 1982. (1882)

AXT, Gunter. Coronelismo indomável: o sistema de relações de poder. In: GOLIN, Tau; BOEIRA, Nelson (Coord.); RECKZIEGEL, Ana; AXT, Gunter (dir.). República Velha (1889-1930). Passo Fundo: Méritos, 2007. V. 3, t. 1.

BOEIRA, Nelson. O Rio Grande de Augusto Comte. In: DACANAL, J. H. (Org.). RS: Cultura e Ideologia. Porto Alegre: Mercado Aberto, 1980.

CERTEAU, Michel de. A escrita da história. Rio de Janeiro: Forense Universitária, 2007.

CEZAR, Temístocles. Como deveria ser escrita a história do Brasil no século XIX. Ensaio de história intelectual. In: PESAVENTO, Sandra (Org.) História cultural: experiências de pesquisa. Porto Alegre: Ed. da UFRGS, 2003.

GUTFREIND, Ieda. Historiografia rio-grandense. Porto Alegre: Ed. Universidade/UFRGS, 1992.

HRUBY, Hugo. O século XIX e a escrita da história do Brasil: diálogos na obra de Tristão de Alencar Araripe (1867-1895). Tese (Doutorado em História). - Pontifícia Universidade Católica do Rio Grande do Sul (PUCRS), Porto Alegre, 2012.

LAZZARI, Alexandre. Entre a grande e a pequena pátria: literatos, identidade gaúcha e nacionalidade (1860/1910). 2004, 363 f. Tese (Doutorado em História) - Universidade Estadual de Campinas (Unicamp), Campinas, 2004.

LOVE, Joseph. O regionalismo gaúcho e as origens da revolução de 30. São Paulo: Perspectiva, 1975.

MARTINS, Ari. Escritores do Rio Grande do Sul. Porto Alegre: EDUFRGS; Instituto Estadual do Livro, 1978.

MARTINS, Jefferson Teles. O Instituto Histórico e Geográfico do Rio Grande do Sul e o espaço social dos intelectuais: trajetória institucional e 
estudo das redes de solidariedade (e conflitos) entre intelectuais (1920-1956). 2015. 280 f. Tese (Doutorado em História) - Pontifícia Universidade Católica do Rio Grande do Sul (PUCRS), Porto Alegre, 2015.

PICCOLO, Helga. Da descolonização à consolidação da República: a questão do separatismo versus federação no Rio Grande do Sul, no século XIX. Indicadores econômicos FEE, Porto Alegre, v. 21, n. 3, p. 148-158, 1993.

RODRIGUES, Mara Cristina. A releitura do passado farroupilha no IHGB (1921-1935): memória republicana e legitimidades intelectuais. Revista Tempo, v. 19, n. 35, jul.-dez. p. 161-183, 2013.

SACCOL, Tassiana Maria Parcianello. Um propagandista da República: política, letras e família na trajetória de Joaquim Francisco de Assis Brasil: década de 1880. 2013. 212 f. Dissertação (Mestrado em História). - Pontifícia Universidade Católica do Rio Grande do Sul (PUCRS), Porto Alegre, 2013.

SILVA, Camila. Do passado ao futuro: a escrita comemorativa do Centenário Farroupilha na imprensa porto-alegrense. Dissertação (Mestrado em História). Universidade do Vale do Rio dos Sinos (Unisinos), São Leopoldo, RS, 2012.

SILVA, Jaisson Oliveira da. A epopeia dos titãs do pampa: historiografia e narrativa épica na História da Grande Revolução de Alfredo Varella. Dissertação de mestrado. PPGH em História, UFRGS, Porto Alegre, 2010.

SOARES, Fabrício A. A. Farrapos de estórias: romance e historiografia da Farroupilha (1841-1999). Tese (Doutorado em História). - Pontifícia Universidade Católica do Rio Grande do Sul (PUCRS), Porto Alegre, 2016.

SOUZA, J. P. Coelho de. O sentido e o espírito da Revolução Farroupilha. Porto Alegre: Globo, 1945. (1936).

TOVO, Fábio Caetano. "Aceitamos a causa dos vencidos como bandeira de futuras vitórias": a memória da Revolução Farroupilha na propaganda republicana de Joaquim Francisco de Assis Brasil. Dissertação (Mestrado em História). - Universidade do Vale do Rio dos Sinos (Unisinos), São Leopoldo, RS, 2019.

VARELA, Alfredo. História da grande revolução: o ciclo farroupilha no Brasil. Porto Alegre: Globo, 1933. 6 v.

Recebido em: 24 de março de 2020 Aceito em: 26 de março de 2021 